Научная статья

УДК 331.225

DOI 10.18101/2304-4446-2021-4-76-83

\title{
О МАТЕРИАЛЬНОМ СТИМУЛИРОВАНИИ РЕЗУЛЬТАТОВ ТРУДА РУКОВОДИТЕЛЕЙ ФАКУЛЬТЕТОВ, ИНСТИТУТОВ
}

\author{
(С) Лисутин Олег Александрович \\ начальник финансово-экономического управления, \\ Алтайский государственный педагогический университет \\ Россия, 656031, г. Барнаул, ул. Молодежная, 55 \\ bul-loa@altspu.ru
}

В статье описывается один из вариантов мотивации труда деканов факультетов и директоров институтов посредством системы материального стимулирования, нацеленной на повышение привлекательности образовательных программ высшего образования среди различных категорий абитуриентов, а также сохранности контингента обучающихся и трудоустройства выпускников факультетов и институтов. Тема исследования актуальна в части теоретического и практического осмысления новых подходов к стимулированию труда работников руководящего состава университета, способствующих усилению внимания к абитуриентам и обучающимся вуза. Внедрение в систему стимулирования описанных в работе показателей эффективности также способствует повышению финансового благосостояния образовательной организации через увеличение численности обучающихся и сохранность контингента обучающихся, что позволяет не допустить сокращение работников вуза.

Ключевые слова: мотивация труда, материальное стимулирование труда, показатели эффективности, контрольные цифры приема, деканы факультетов, директора институтов.

\section{Для цитирования}

Лисутин О. А. О материальном стимулировании результатов труда руководителей факультетов, институтов // Вестник Бурятского государственного университета. Экономика и менеджмент. 2021. № 4. С. 76-83.

Введение. Материальное стимулирование работников имеет важное значение в управлении и развитии любой организации. Не является исключением и образовательные организации высшего образования, затраты на оплату труда с учетом страховых взносов, в которых зачастую составляют не менее $70 \%$ всех ежегодных расходов вуза без учета целевых средств на выплату стипендий и реализацию целевых мероприятий. В каждом вузе выстраиваются индивидуальные системы стимулирования, способствующие приблизить вуз к достижению целей и выполнению задач, зафиксированных в программе развития образовательной организации. Зачастую в системах стимулирования используются показатели, результаты выполнения которых направлены на развитие научной, образовательной и воспитательной деятельности. Результаты по данным направлениям безусловно важны для вуза, поскольку производится оценка достижений по основным видам деятельности.

В настоящее время исследователями предлагается множество моделей систем стимулирования, способствующих решению определенных задач. Так 
О. А. Лисутин. О материальном стимулировании результатов труда руководителей факультетов, институтов

Т. А. Смирновой и Я. М. Янченко проведен анализ стимулирования труда в Сибирском федеральном университете. Выявлены недостатки существующей системы и предложен авторский подход к ее совершенствованию. Авторами предложены трехуровневый механизм распределения показателей эффективности и коэффициенты, регулирующие изменчивость показателей, устанавливаемых университетом [1, с. 869].

Практическими рекомендациями, сформулированными в статье И. А. Бедрачука и О. В. Митиной, стало описание этапов работы по переходу на «эффективные контракты» с преподавателями вуза в части разработки и уточнения функционала работников. Основной составляющей контракта являются выплаты стимулирующего характера, увязанные с показателями эффективности работы вуза и достижением его стратегических целей [2, с. 39]. В. В. Муравлев предлагает схему распределения стимулирующих фондов работников профессорскопреподавательского состава в зависимости от занятой рейтинговой позиции участником рейтингования, которая позволит нивелировать пиковые значения лидеров по показателю, что позволит более точно и справедливо распределить фонд материального стимулирования [3, с. 1]. В рамках совершенствования системы материального стимулирования, нацеленной на обеспечение повышения качества образовательных услуг, А. И. Бушуева предлагает осуществлять компенсацию части расходов по потребительскому или ипотечному кредиту для сотрудников организации высшего образования [4, с. 11].

В работе «Стимулирование руководящего состава государственного вуза с использованием комплексной системы показателей» авторами рассматривается комплексный подход к стимулированию руководящего состава государственного вуза с целью повышения качества и результативности его деятельности. В том числе предлагается ряд показателей, оценивающих результаты деятельности директоров институтов системы высшего профессионального образования [5, c. 41]. В данной работе предложен иной перечень показателей оценки деятельности руководителей факультетов и институтов, направленный на оценку результатов труда руководящих должностей профессорско-преподавательского состава, способствующий увеличению бюджетных контрольных цифр приема, выделяемых учредителем для университета, а также повышающий эффективность внебюджетной деятельности подразделения, находящегося под руководством декана факультета или директора института.

\section{О системе стимулирования результатов труда}

В 2020 г., Министерством науки и высшего образования Российской Федерации был разработан и утвержден Порядок проведения конкурса на распределение контрольных цифр приема по специальностям и направлениям подготовки и (или) укрупненным группам специальностей и направлений подготовки для обучения по образовательным программам высшего образования за счет бюджетных ассигнований федерального бюджета (далее - Порядок) ${ }^{1}$. От выполнения пока-

\footnotetext{
${ }^{1}$ Об утверждении Порядка проведения конкурса на распределение контрольных цифр приема по специальностям и направлениям подготовки и (или) укрупненным группам специальностей и направлений подготовки для обучения по образовательным программам высшего образования за счет бюджетных ассигнований федерального бюджета: приказ Минобрнауки России от 03.04.2020 № 550 (ред. от 30.11.2020).
} 
зателей эффективности, указанных в данном документе, зависит объем выделяемых государством бюджетных контрольных цифр приема, что напрямую связано с благосостоянием, дальнейшим существованием и развитием каждого образовательного учреждения высшего образования Российской Федерации.

Безусловно, в соответствии с результатами выполнения данных показателей можно производить распределение доводимых до вуза контрольных цифр приема внутри учреждения между факультетами, институтами, формируя бюджетные места по образовательным программам. Данный подход может пагубно повлиять на востребованные в регионе специальности и направления подготовки, оставляя экономические отрасли без обновления кадров. Поэтому считаем, что с целью недопущения сокращения образовательных программ, востребованных в субъектах Российской Федерации и обществе в целом, основные показатели, используемые в методике оценки выполнения показателей реализации специальностей и направлений подготовки, нужно применять при разработке системы стимулирования работников, осуществляющих управление образовательными подразделениями, тем самым мотивируя руководящий состав университета на выполнение представленных в Порядке показателей эффективности.

Система оплаты труда деканов факультетов, директоров институтов может состоять из постоянной (окладной) части и переменной части, начисляемой единоразово или устанавливаемой на определенный период времени.

Единоразовые выплаты предпочтительно устанавливать за индивидуальные результаты в части научной, учебной, воспитательной или профориентационной деятельности. За выполнение показателей эффективности описанных в данной работе целесообразно устанавливать стимулирующие надбавки, действующие определенный период, например в течение учебного года. В этом случае стимулирование будет иметь более весомое значение для работника, занимающего руководящую должность, что приведет к планомерной работе по достижению высоких результатов в части выполнения показателей, оцениваемых по результатам набора обучающихся на первый курс и трудоустройство выпускников.

К показателям эффективности, по итогам оценки результатов выполнения которых предлагается устанавливать стимулирующие надбавки деканам факультетов и (или) директорам институтов на период учебного года, можно отнести следующие шесть показателей.

1. Средний балл единого государственного экзамена (далее - ЕГЭ) студентов, принятых на обучение по основной образовательной программе высшего образования учебного подразделения (далее - ООПУП) очной формы, рассчитывается по следующей формуле:

$$
P e=\frac{E a p}{Q a p},
$$

где $P e-$ средний балл ЕГЭ абитуриентов, зачисленных на первый курс очной формы обучения ООПУП;

$E_{a p}$ - сумма баллов ЕГЭ абитуриентов, зачисленных на первый курс очной формы обучения ООПУП бакалавриата и специалитета на бюджетной и внебюджетной основе;

$Q_{a p}$ - количество абитуриентов, зачисленных на первый курс очной формы обучения ООПУП бакалавриата и специалитета на бюджетной и внебюджетной основе. 
O. А. Лисутин. О материальном стимулировании результатов труда руководителей факультетов, институтов

Высокий балл ЕГЭ абитуриентов, зачисляемых на первый курс обучения, является стратегически важным фактором для любого вуза, поскольку этот фактор служит индикатором репутации и востребованности основной образовательной программы, факультета, института и образовательной организации в целом.

Предлагаемый к использованию показатель имеет прямую взаимосвязь с одноименным показателем Порядка проведения конкурса по распределению бюджетных КЦП, а также имеет сходство с критерием оценки эффективности образовательной деятельности организаций высшего образования ${ }^{1}$.

2. Уровень трудоустройства выпускников факультета (института), рассчитывается по формуле:

$$
P e=\frac{E g}{G S} \times 100,
$$

где $P e-$ процент трудоустройства выпускников факультета (института) очной формы, окончивших обучение по образовательным программам высшего образования факультета (института) в году предшествующем отчетному году;

$E g$ - количество выпускников факультета (института) очной формы, окончивших обучение по образовательным программам высшего образования института, факультета в году предшествующем отчетному году и трудоустроившихся в отчетном году (за исключением продолживших обучение по образовательным программам высшего образования), являющихся гражданами Российской Федерации;

Gs - количество выпускников факультета (института) очной формы, окончивших обучение по образовательным программам высшего образования института, факультета в году предшествующем отчетному году (за исключением продолживших обучение по образовательным программам высшего образования), являющихся гражданами Российской Федерации.

Уровень трудоустройства выпускников, как и средний балл ЕГЭ, является основным показателем, используемым при распределении бюджетных контрольных цифр приема по специальностям и направлениям подготовки и (или) укрупненным группам специальностей и направлений подготовки бакалавриата и специалитета. Успехи и достижения вузов в вопросе трудоустройства своих выпускников влияют на повышение привлекательности образовательной организации на рынке образовательных услуг для выпускников школ, абитуриентов.

3. Уровень реализации дополнительного образования на факультете (в институте) рассчитывается по формуле:

$$
A e=\frac{P d+P r}{S} \times 100,
$$

где $A e$ - процент студентов очной формы обучающихся на последнем курсе, получивших дополнительное образование в период обучения по образовательным программам высшего образования на факультете, в институте;

$P d$ - количество студентов факультета (института) обучающихся на последнем курсе очной формы, прошедших обучение в образовательной организации по программам повышения квалификации;

\footnotetext{
${ }^{1}$ Методика расчета показателей мониторинга эффективности образовательных организаций высшего образования 2018 года Министра образования и науки Российской Федерации от 30.03.2018 г. № ик-139/05вн.
} 
$\mathrm{Pr}$ - количество студентов факультета (института) обучающихся на последнем курсе, прошедших обучение в образовательной организации по программам профессиональной переподготовки;

$\mathrm{S}$ - общее количество студентов факультета (института), очной формы, обучающихся на последнем курсе.

Возможность получения студентом дополнительного образования параллельно обучению по основной образовательной программе высшего образования нельзя переоценить. Дополнительное образование является несомненным бонусом для обучающихся, позволяющим расширить профессиональные компетенции студентов, получить личностный рост и иметь запасной вариант трудоустройства. Кроме того, оказание вузом услуг дополнительного образования, является привлекательным фактором и для абитуриентов, потенциальных первокурсников, рассматривающих вузы при подаче документов на зачисление.

4. Региональный географический уровень востребованности образовательных программ факультета (института) рассчитывается по следующей формуле:

$$
G r=\frac{F r}{F o} \times 100,
$$

где $G r$ - Расширение географии обучающихся на факультете, в институте первого курса обучения (региональный уровень);

$F_{r}$ - количество граждан Российской Федерации, зачисленных на первый курс образовательной программы факультета (института), зарегистрированных по месту жительства в регионах, отличных от региона, в котором расположен вуз;

$F_{o}$ - общее количество обучающихся, зачисленных на первый курс образовательной программы факультета (института).

Результаты данного показателя являются индикатором востребованности образовательных программ факультета (института) среди абитуриентов, окончивших школы в иных регионах.

5. Международный географический уровень востребованности образовательных программ факультета (института) рассчитывается по следующей формуле:

$$
G i=\frac{F i}{\text { Fo }} \times 100,
$$

где $G_{i}$ - расширение географии обучающихся (международный уровень);

$F_{i}$ - количество иностранных граждан, зачисленных на первый курс образовательной программы факультета (института);

$F_{o}$ - общее количество обучающихся зачисленных на первый курс образовательной программы факультета (института).

«Развитие экспортного потенциала высшего образования признается одним из важнейших стратегических направлений государственной политики России. Усиление авторитета российского высшего образования, повышение привлекательности российских вузов на мировом образовательном рынке повышает конкурентоспособность системы национального образования, усиливает позиции страны в мировом сообществе за счет распространения достижений отечественной науки, национальной культуры» [6, с. 21].

6. Эффективность внебюджетной деятельности факультета (института) рассчитывается по следующей формуле: 
O. А. Лисутин. О материальном стимулировании результатов труда руководителей факультетов, институтов

$$
E i=\frac{I f}{\mathrm{Nw}} \times 100
$$

где $E i$ - сумма внебюджетного дохода факультета (института) на одну штатную единицу профессорско-преподавательского состава за учебный год;

If - сумма внебюджетного дохода факультета (института) за отчетный учебный год полученная от коммерческой деятельности факультета (института);

$\mathrm{Nw}$ - штатная численность работников профессорско-преподавательского состава на первое сентября отчетного года.

Внебюджетная деятельность факультета (института) способствует повышению финансовой устойчивости образовательной организации высшего образования. Финансовые поступления от оказания платных услуг (работ) имеют весомый объем в доходной части бюджета образовательной организации. В ряде вузов доход от внебюджетной деятельности достигает 50-60\% общего объема финансовых поступлений. При этом более $70 \%$ всех внебюджетных доходов вуза это доходы от образовательной и исследовательской деятельности факультетов (институтов).

Для каждого из предложенных показателей вузом устанавливаются минимальные и максимальные результирующие значения, которые сопоставляются с фактическими результатами выполнения показателей в начале каждого учебного года. Минимальные значения результатов выполнения показателей могут соответствовать пороговым мониторинговым значениям, применяемым органами исполнительной власти при проведении мониторингов эффективности деятельности образовательных организаций высшего образования. В качестве пороговых уровней результатов выполнения показателей, позволяющих деканам и директорам претендовать на назначение стимулирующих выплат, также могут применяться медианные, среднеарифметические и рейтинговые значения выполнения показателей эффективности, являющиеся следствием анализа результатов данных по всем факультетам и институтам вуза. Ориентиром для определения максимального значения стимулирующей выплаты руководителя учебного подразделения могут служить максимальные пороговые значения устанавливаемые в мониторинге эффективности деятельности образовательных организаций высшего образования или значения, устанавливаемые вузом самостоятельно в программе развития.

Результаты всех вышеперечисленных показателей предлагается аннулировать в случае невыполнения учебным подразделением набора на бюджетные КЦП в соответствии с доведенным до вуза лимитом бюджетных мест на текущий учебный год.

Размер стимулирующих выплат деканов факультетов, директоров институтов также может корректироваться в меньшую или большую сторону исходя из результатов сохранности бюджетного контингента обучающихся. При этом в случае выполнения государственного задания на $100 \%$ размер общей стимулирующей выплаты индексируется в большую сторону, а в случае невыполнения в полном объеме государственного задания размер стимулирующей выплаты снижается вплоть до полного аннулирования выплаты. Корректировка размера стимулирующей надбавки выполняется на основании данных отчета о выполнении государственного задания формируемого до 1-го февраля каждого года. 


\section{Заключение}

Предлагаемая система показателей эффективности стимулирующих деятельность деканов факультетов и директоров институтов вуза, на наш взгляд, является необходимым дополнением к имеющимся в вузах вариациям механизмов финансового стимулирования. Представленные в работе показатели усиливают заинтересованность руководителей учебных подразделений к вопросам, связанным с проведением ежегодной приемной кампании, взаимодействию с потенциальными для выпускников вуза работодателями и усилению внимания к обучающимся в образовательной организации с целью сохранности бюджетного контингента и недопущения пустой траты бюджетных средств в случае досрочного отчисления обучающихся.

\section{Литература}

1. Смирнова Т. А., Янченко Я. М. Совершенствование системы мотивации и стимулирования труда преподавателей высшей школы // Региональная экономика: теория и практика. 2018. № 5(452). С. 869-883. Текст: непосредственный.

2. Бедрачук И. А., Митина О. В. Эффективный контракт с преподавателем как инструмент повышения эффективности деятельности вуза // Университетское управление: практика и анализ. 2015. № 1(95). С. 39-52. Текст: непосредственный.

3. Муравлев В. В. Материальное стимулирование профессорскопреподавательского состава на основе оценки результатов деятельности // Вестник евразийской науки. 2017. № 2(39). С. 1-8. Текст: непосредственный.

4. Бушуева А. И. Система стимулирования труда профессорско-преподавательского состава организации высшего образования как стратегический инструмент обеспечения качества образовательных услуг // Вестник РУК. 2018. №3 (33). С. 11-17. Текст: непосредственный.

5. Митина О. В., Межонова Л. В., Бедрачук И. А. Стимулирование руководящего состава государственного вуза с использованием комплексной системы показателей // Университетское управление: практика и анализ. 2013. №2 (84). С. 41-51. Текст: непосредственный.

6. Галямова Э. Ф., Кудимана Г. О. Привлекательность российских вузов на международном рынке образовательных услуг // Вестник Удмуртского университета. Серия. Экономика и право. 2017. Т. 27, № 3. С. 21-26. Текст: непосредственный.

Статья поступила в редакцию 30.08.2021; одобрена после рецензирования 29.10.2021; принята к публикации 01.11.2021

\section{ON IMPACT OF MATERIAL INCENTIVES ON JOB PERFORMANCE OF THE HEADS OF FACULTIES AND INSTITUTES}

Oleg A. Lisutin

Head of Financial and Economic Department, Altai State Pedagogical University

55 Molodezhnaya St., Barnaul 656031, Russia

bul-loa@altspu.ru

Abstract. The article describes a possibility for motivating the labour of deans of faculties and directors of institutes through a system of material incentives aimed at increasing the attractiveness of educational programs of higher education among various categories of applicants, as well as at continuity of the student body and employment of graduates from facul- 
O. А. Лисутин. О материальном стимулировании результатов труда руководителей факультетов, институтов

ties and institutes. The research is relevant in terms of theoretical and practical comprehension of new approaches to stimulation of the labour of university's senior personnel, contributing to closer attention to applicants and students. The introduction of the performance indicators described in the work into the incentive system also contributes to the financial well-being of an educational organization through an increase in the number of students and continuity of the student body. All these make it possible to prevent the reduction of university employees.

Keywords: employee motivation, material incentive, performance indicators, admission quotas, deans of faculties, directors of institutes.

\section{For citation}

Lisutin O. A. On Impact of Material Incentives on Job Performance of the Heads of Faculties And Institutes. Bulletin of Buryat State University. Economy and Management. 2021; 4 : 76-83 (In Russ.).

The article was submitted 30.08.2021; approved after reviewing 29.10.2021; accepted for publication 01.11.2021. 